\title{
Isolation and characterization of Clostridium perfringens strains isolated from ostriches (Struthio camelus) in Vietnam
}

\author{
Tham Thi Nguyen ${ }^{1}$ (D), Hung Vu-Khac ${ }^{2}$ and Tan Duc Nguyen $^{1}$ (D) \\ 1. Department of Technology and Development Product, Institute of Veterinary Research and Development of Central \\ Vietnam, Nha Trang City, Vietnam; 2. Department of Biotechnology, Institute of Veterinary Research and Development of \\ Central Vietnam, Nha Trang City, Vietnam. \\ Corresponding author: Hung Vu-Khac, e-mail: vukhac68@hotmail.com \\ Co-authors: TTN: thamtb87@gmail.com, TDN: ductanpvty@yahoo.com \\ Received: 17-04-2020, Accepted: 30-06-2020, Published online: 25-08-2020
}

doi: www.doi.org/10.14202/vetworld.2020.1679-1684 How to cite this article: Nguyen T, Vu-Khac H, Nguyen TD (2020) Isolation and characterization of Clostridium perfringens strains isolated from ostriches (Struthio camelus) in Vietnam, Veterinary World, 13(8): 1679-1684.

\begin{abstract}
Background and Aim: Clostridium perfringens can cause enteritis in ostriches. The toxin release is believed to play a major role in determining pathogenesis properties of these pathogenic bacteria. This study was conducted to isolate and characterize $C$. perfringens strains from ostriches in Vietnam for identifying if particular virulence factors of these pathogenic bacteria are associated with enteritis progress in ostriches.
\end{abstract}

Materials and Methods: The prevalence of $c p a, c p b, i A$, etx, $c p e$, and $c p b 2$ genes among C. perfringens isolates was determined by a multiplex polymerase chain reaction (PCR) method. The NetB toxin-encoding gene was detected by PCR and then sequenced to observe their variation. The expression of NetB toxin was checked by SDS-PAGE.

Results: A total of 116 C. perfringens isolates were obtained from 318 fecal samples and 105 intestinal organs. Of 80 isolates from fecal samples, 33 isolates were from healthy and 47 isolates were from diseased ostriches. The results of multiplex PCR showed that all 116 C. perfringens strains from healthy and enteric disordered ostriches were positive for the alpha toxin-encoding gene ( $c p a$ ). The $c p e$ and $c p b 2$ genes were found in only one and five diseased ostriches, respectively. The $n e t B$ gene was detected in 1/33 (3.03\%) C. perfringens isolates from healthy ostriches, in 8/47 (17.05\%) isolates from feces, and in 7/36 (19.44\%) intestinal contents of diseased ostriches. The full-length sequences of 5 out of 15 net $B$-positive isolates from diseased ostriches showed $100 \%$ identity to each other as well as to the $n e t B$ sequences available in GenBank. All of these five isolates produced NetB toxin in vitro.

Conclusion: Type A is the most prevalent among C. perfringens isolates from ostriches in Vietnam. Especially, the study provides data emphasizing the role of NetB toxin in causing necrotic enteritis by $C$. perfringens in ostriches.

Keywords: Clostridium perfringens, multiplex polymerase chain reaction, ostriches, toxin genes.

\section{Introduction}

Clostridium perfringens can cause enteritis in ostrich chicks $[1,2]$. The bacterium is a normal inhabitant of the gut, and predisposing stress factors such as change of diet are thought to lead to its proliferation leading to the disease condition [2]. C. perfringens strains were previously classified into five specific toxinotypes (A-E) [3-5]. However, in a recent study, they have been proposed for seven toxinotypes (A-G) dependent on which major toxins ( $\alpha$ - cpa, $\beta$ - cpb, $\varepsilon$ - etx, l - iap, CPE - cpe, and NetB - netB) they produced $[5,6]$. The release of these toxins is believed to play a major role in determining pathogenesis properties of C. perfringens $[4,7]$. The role of other toxins produced by $C$. perfringens, such as enterotoxin and beta 2 toxin, in causing enteritis is considered to be less significant $[7,8]$, whereas the

Copyright: Nguyen, et al. Open Access. This article is distributed under the terms of the Creative Commons Attribution 4.0 International License (http://creativecommons.org/licenses/ by/4.0/), which permits unrestricted use, distribution, and reproduction in any medium, provided you give appropriate credit to the original author(s) and the source, provide a link to the Creative Commons license, and indicate if changes were made. The Creative Commons Public Domain Dedication waiver (http:// creativecommons.org/publicdomain/zero/1.0/) applies to the data made available in this article, unless otherwise stated.
NetB toxin has been implicated as the major contributing factor to enteritis in chickens although other complementary factors may still exist [8-11].

In Vietnam, raising ostriches have been started since 1995, the ostrich breeding was imported from Zimbabwe and Australia [10]. According to data from General Statistics Office of Vietnam, in 2018, there were 56 provinces and cities situated in Vietnam involved in ostrich farming, providing 4660.1 million ostriches to slaughters. The symptoms of enteritis have been reported in ostrich farms in Vietnam; however, there is no report on the prevalence of $C$. perfringens in ostrich farms and hence no molecular characterization of this bird-derived isolates.

The present study investigated the prevalence of $C$. perfringens among ostriches raised in Vietnam. Toxinotypes and NetB production of the isolated C. perfringens were characterized to understand their potential pathogenic properties.

\section{Materials and Methods}

\section{Ethical approval}

The approval from the Institutional Animal Ethics Committee to carry out this study was not required as no invasive technique was used. 


\section{Study period and location}

The study was conducted from January 2016 to January 2019. We collected fecal and intestinal samples from ostrich farms located at Quang Binh, Quang Nam and Khanh Hoa provinces of Vietnam. The samples were transported on ice to the Department of Technology and Development Product, Institute of Veterinary Research and Development of Central Vietnam for testing.

\section{Sample collection and $\boldsymbol{C}$. perfringens strains}

A total of 318 fecal samples ( 158 from healthy and 160 from suspected necrotic enteritis [NE] ostriches which showed anorexia, ruffled feathers, depression, diarrhea, and listlessness) and 105 intestinal organs (small intestine, colon, and cecum) with typical lesions (thin intestinal wall, filled with gas, confluent mucosal necrosis of the small intestine, and depressed ulcers in the mucosal surface) were collected. The fecal samples were streaked onto blood agar plates containing $7 \%$ sheep blood agar and incubated in an anaerobic chamber at $37^{\circ} \mathrm{C}$ for $48 \mathrm{~h}$. Colonies which showed dual hemolytic zones were picked and subcultured in Tryptose Sulfite Cycloserine agar (TSC agar, Oxoid, Merck) for purification and were grown in fluid thioglycollate (FTG, Merck) for toxin production. For the intestinal organs, samples were taken by scrubbing the intestinal inner wall of affected ostriches with cotton swabs then processed in the same way as fecal samples. The identity of the isolates was confirmed by their colonial and microscopical morphology, hemolytic pattern, Gram staining, and biochemical tests as previously described [12]. Each C. perfringens isolate from one ostrich was selected for further study.

\section{Determination of toxin-encoding genes of}

\section{C. perfringens isolates}

The multiplex polymerase chain reaction (PCR) reactions detecting $c p a, c p b, i A$, etx, cpe, and $c p b 2$ genes were performed as described by Songer and Bueschel [13]. The PCR reaction for netB detection was carried out as described by Keyburn et al. [10]. All primers applied in this study are listed in Table-1 $[11,14,15]$.

\section{Total DNA extraction}

A single colony of each $C$. perfringens strain was suspended in $200 \mu \mathrm{L}$ distilled water, boiled for $10 \mathrm{~min}$, and then centrifuged at $10,000 \times \mathrm{g}$ for $10 \mathrm{~min}$. The supernatants were collected and used as template DNA for PCR reactions.

\section{DNA sequencing of net $B$ gene}

The DNA samples were subjected to netB gene amplification reaction using netB(-100) $\mathrm{F}$ and netB(1278) $\mathrm{R}$ primers (Table-1) [14]. The PCR products were purified using QIAquick Gel Extraction Kit (QIAGEN Germany) according to the manufacture's instruction and sent to $1^{\text {st }} \mathrm{BASE}$ - Singapore for sequencing.

\section{NetB toxin production and purification}

C. perfringens isolates were cultured, supernatant harvested, and protein purified as described by Keyburn et al. [10]. The NetB protein (detected at approximately $33 \mathrm{kDa}$ ) was analyzed by SDS-PAGE. The protocol for SDS-PAGE was used as described in "A Guide to Polyacrylamide Gel Electrophoresis and Detection, BIO-RAD".

\section{Results}

Isolation of $C$. perfringens infected in ostrich farms in Vietnam

A total of $116 C$. perfringens isolates were obtained from 318 fecal samples and 105 intestinal organs. Of 80 isolates from fecal samples, 33 isolates were recovered from healthy ostriches and 47 isolates came from disordered birds. Only one isolate from each ostrich was considered. The results of biochemical tests proved that all bacterial isolates exhibited the characteristic features of $C$. perfringens as documented [12].

\section{Prevalence of toxin-encoding genes among C. perfringens isolates}

The results of multiplex PCR showed that all C. perfringens strains regardless of sourced from healthy and enteric disordered ostriches were positive for the alpha-toxin gene (cpa) (Figure-1). The cpe gene which encodes $C$. perfringens enterotoxin was found

Table-1: Primers applied in polymerase chain reactions detecting Clostridium perfringens toxin genes.

\begin{tabular}{|c|c|c|c|c|}
\hline Toxin & Primer & Nucleotide sequence & Amplicon size (bp) & References \\
\hline \multirow[t]{2}{*}{$\alpha$-Toxin } & Cpa-F & GCTAATGTTACTGCCGTTGA & 324 & [14] \\
\hline & Cpa-R & CCTCTGATACATCGTGTAAG & & \\
\hline \multirow[t]{2}{*}{$\beta$-Toxin } & Cpb-F & GCGAATATGCTGAATCATCTA & 196 & \\
\hline & Cpb-R & GCAGGAACATTAGTATATCTTC & & \\
\hline \multirow[t]{2}{*}{$\varepsilon$-Toxin } & etx-F & GCGGTGATATCCATCTATTC & 655 & \\
\hline & etx-R & ССАСТTACTTGTССТАСТАAC & & \\
\hline \multirow[t]{2}{*}{ I-Toxin } & $\mathrm{iA}-\mathrm{F}$ & ACTACTCTCAGACAAGACAG & 446 & \\
\hline & $\mathrm{iA}-\mathrm{R}$ & СТTТССТТСТАТТАСТАТАCG & & \\
\hline \multirow[t]{2}{*}{ Cpe } & Cpe-F & GGAGATGGTTGGATATTAGG & 233 & \\
\hline & Cpe-R & GGACCAGCAGTTGTAGATA & & \\
\hline \multirow[t]{2}{*}{ Cpb2 } & Cpb2-F & AGATTITAAATATGATCCTAACC & 567 & \\
\hline & Cpb2-R & СААТАСССТТСАССАААТАСТС & & \\
\hline \multirow[t]{2}{*}{ netB } & netB- $F$ & GCTGGTGCTGGAATAAATGC & 384 & {$[11]$} \\
\hline & netB-R & TCGCCATTGAGTAGTTTCCC & & \\
\hline \multirow[t]{2}{*}{ netB (for sequencing) } & netB $(-100) \mathrm{F}$ & CCAGTTATGTATAAATTITGACCAGTT & 1378 & {$[15]$} \\
\hline & netB $(1278) R$ & AAACTTTAGTATTCСТСТСАTITITATCCC & & \\
\hline
\end{tabular}


in only one isolate from the diseased ostrich. As stated by the new typing scheme of Rood et al. [6], this strain belongs to type $\mathrm{F}$ as it carried both cpa and cpe genes. The gene encoding CPB2 toxin was detected in five diseased ostriches (three from fecal and two from intestinal samples). The PCR results of net $B$ detection (Figure-2) recognized 16 strains positive for this gene. Except one strain carrying all three genes of cpa, cpe, and netB, 15 left strains were classified as type $G$ following the Rood's typing [6]. Our study also showed a clear difference of net $B$ prevalence between the $C$. perfringens isolates from healthy and diseased birds. There were only $1 / 33(3 \%)$ isolates from healthy ostriches detected for net $B$ gene while 8/47 (17.05\%) and 7/36 (19.44\%) isolates, respectively, from fecal and intestinal samples of diseased birds positive for this gene.

\section{Analysis of netB sequences}

We selected 5 out of 15 netB-positive isolates from diseased ostriches for $n e t B$ amplification and sequencing. The analyzed sequences cover both the $969 \mathrm{bp}$ coding sequence (CDS) region and $60 \mathrm{bp}$ upstream promoter region including sequences potentially representing the RNA polymerase/sigma factor recognition sites (35: TTGAAA; 10: TATAAT) as well as the ribosomal binding site (AGGAGG). All the sequences derived from five isolates (GenBank accession number MT 032260-MT 032264) showed $100 \%$ identity to each other as well as to the netB sequences presently available in GenBank. No nucleotide variations in the CDS and promoter regions were

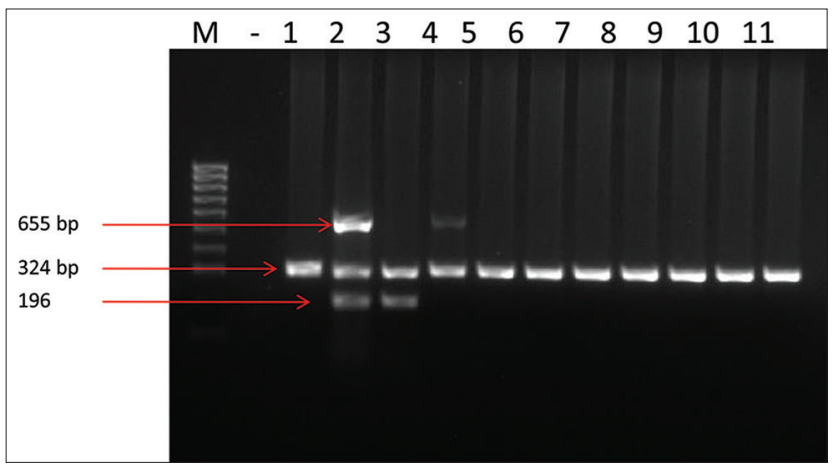

Figure-1: Multiplex polymerase chain reaction for toxins typing of $C$. perfringens. M: 100 bp DNA ladder maker, (-) negative control, lane 1: Positive control for type $A$, lane 2 : Positive control for type B, lane 3: Positive control for type C, lane 4: Positive control for type D, lane 5-11: Samples.

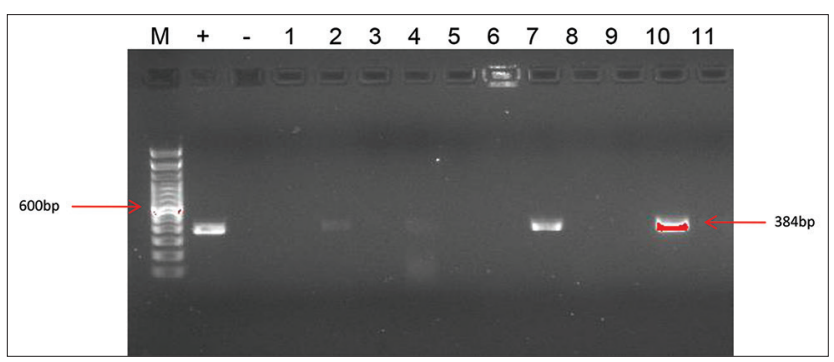

Figure-2: Polymerase chain reaction for net $B$ gene detection. M: 100 bp DNA ladder, (+): Positive control, (-): Negative control, lane 1-11: Samples, lane 7, 10: Positive for netB gene. observed. These results indicated that regardless of their geographic origin, $n e t B$ gene is conserved among C. perfringens.

\section{Production of NetB toxin in C. perfringens isolates}

Five net $B$-positive isolates from diseased ostriches and one isolate from healthy bird were selected for testing NetB toxin production in vitro. These strains were cultured for supernatant harvest, NetB toxin purified, and inspected on Coomassie bluestained SDS-PAGE gel (Figure-3). All five isolates from diseased ostriches showed accumulated amount of NetB toxin in the supernatant with a molecular mass of approximately $33 \mathrm{kDa}$ by SDS-PAGE analysis, whereas the net $B$-positive isolate from healthy bird did not produce this toxin.

\section{Discussion}

This study is the first report of the prevalence and toxinotype characterization of $C$. perfringens isolates from ostriches raised in Vietnam. The strain identification was carried out by conventional morphological biochemical tests and toxin-encoding genes of $C$. perfringens isolates were detected by multiplex PCR reactions. The results of isolation showed that C. perfringens infection was found in $20.88 \%(33 / 158)$ healthy ostrich-derived fecal samples and $29.37 \%$ (47/160) of diseased birds. Especially, the infection percentage of $C$. perfringens in diseased ostrich intestine was determined to be higher (34.28\%). The prevalence of $C$. perfringens among healthy ostriches in this study is lower than the result of Alimolaei and Ezatkhah study in Iran, where 46/118 (38,98\%) samples were positive for $C$. perfringens [15]. However, this study showed a higher prevalence of $C$. perfringens in diseased ostriches compared to the result of Keokilwe et al. [16] in South Africa where C. perfringens was detected in only $20 \%(44 / 122)$ samples.

$C$. perfringens type $\mathrm{A}$ is the most common toxinotype in the environment and associated with food poisoning in humans [3]. In this study, we found all

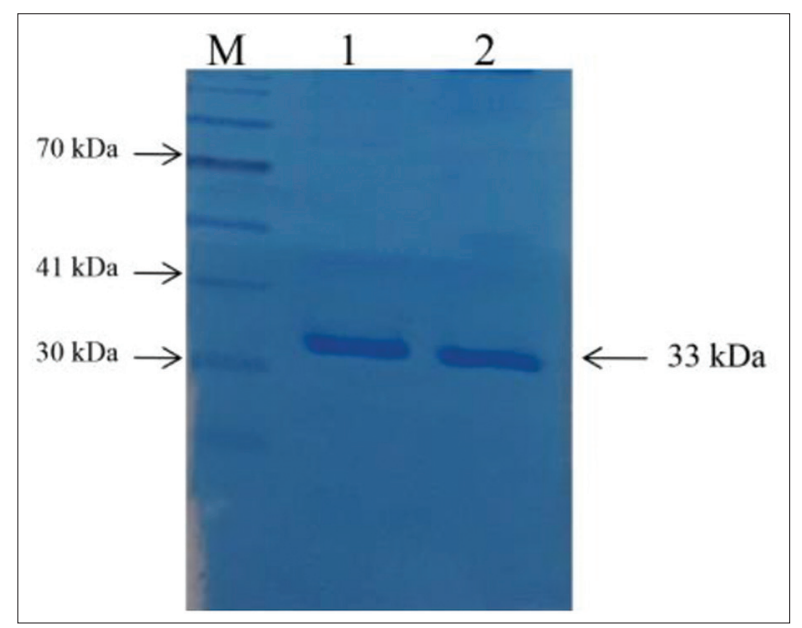

Figure-3: SDS-PAGE of purified NetB toxin stained with Coomassie blue. M: Pre-stained marker, Lanes 1-2: NetBpositive isolates from diseased ostriches. 
116/116 (100\%) C. perfringens strains carrying cpa gene. This finding was in agreement with the previous studies in Iran, where $30 / 30$ C. perfringens isolates [17] and 46/46 C. perfringens isolates [15] were positive with cpa gene. In another study, Keokilwe et al. [16] also found that the cpa gene was the most prevalent $(93,2 \%)$ among $C$. perfringens isolates from ostriches which showed enteritis symptoms in South African. Several studies have indicated that cpe-positive strains of $C$. perfringens from poultry occur in low number and can be less than 5\% of global $C$. perfringens isolates [18-20]. These results are in agreement with our study as we found that only one $C$. perfringens isolate from ostrich was positive with cpe gene. Several studies have shown that the beta- 2 toxin is not a critical factor in $C$. perfringens infection in particular cases of poultry [7,21] as its prevalence was documented to be low in diseased poultry but quite high in healthy ones [7]. In this study, we found only $5(4,31 \%)$ isolates from diseased ostriches carried $c p b 2$ gene. It has been reported by Keyburn et al. [10] that NetB, a pore-forming toxin, is critical to NE development in chickens. They also reported that netB knockout mutants failed to produce NE in chickens, while such mutants complemented with the wild-type netB gene, caused NE. The present study revealed the prevalence of net $B$-positive $C$. perfringens isolates was $17.05 \%$ in fecal and $19.44 \%$ in intestinal samples of diseased ostriches, while only 3.03\% strains from healthy ostriches carried net $B$ genes (Table-2). Our results were in agreement with the investigation carried out in Iran [22], where 8/16 C. perfringens isolates from $\mathrm{NE}$ ostriches were positive for $n e t B$ genes, while none of 20 isolates from healthy birds was positive for this gene. In another study, Keokilwe et al. showed that 7/43 C. perfringens isolates from 1-day to 3-month ostriches with enteritis symptoms were positive with net $B$ genes [16]. The study of Abildgaard et al. has shown that NetB production was only observed in 4 out of 14 net $B$-positive $C$. perfringens isolates recovered from healthy chickens, whereas 12 out of 13 net $B$-positive isolates from NE chickens were determined to produce the NetB toxin [14]. In this study, we also found that all five net $B$-positive isolates from diseased ostriches accumulated NetB toxin in vitro as analyzed by
SDS-PAGE, while the isolate from healthy ostrich did not produce this toxin.

Our results combined with these referenced ones support the suggestion of Keybum et al. [10] that NetB toxin plays an important role in causing enteritis disease in poultry. However, the present study indicated that there is a large population of $C$. perfringens isolates from diseased birds that do not carry net $B$. In agreement with this result, a study in Iran found that only $6.6 \%$ of the isolates from NE case of turkeys (Meleagris gallopavo) positive for $n e t B$ and all isolates from flocks of mynah (Acridotheres tristis) and partridge (Perdix perdix) with severe NE symptoms negative for netB [23]. In another study, Ezatkhah et al. [24] also reported a low prevalence of netB gene $(17.78 \%)$ in the isolates from broiler chickens clinically suspected to $\mathrm{NE}$. According to these findings, NetB toxin may not be an obligate requirement for $C$. perfringens virulence or at least the presence of this toxin may not be essential for the disease process in all C. perfringens isolates. Another possible explanation to consider is that $n e t B$-negative isolates can cause disease in the field either by themselves or as part of a wider microbial consortium. Therefore, NE process with the roles of NetB toxin as well as alternative virulence factors and microflora in the association with C. perfringens needs further investigation.

For a better understanding of the role of NetB toxin role in $C$. perfringens pathogenesis, we sequenced five netB genes of five NetB toxin-producing isolates. The results showed that all of the analyzed sequences showed $100 \%$ identity to each other. No nucleotide variations in the CDS and the promoter regions were observed, indicating that net $B$ gene is conserved among $C$. perfringens isolates in Vietnam. In the case of blasting only the 969 bp CDS region, we found 17 full-length $n e t B$ gene sequences available in GenBank showing $100 \%$ identity to our sequences. However, there was only one sequence from C. perfringens isolate from Denmark (GU433324.1) [14] revealed 100\% identity to our sequences that include both the CDS and promoter regions. We analyzed 20 net $B$ gene sequences, including $\mathrm{CDS}$ and promoter regions available in GenBank to clarify how the net $B$ genes of $C$. perfringens isolates in Vietnam are different

Table-2: Prevalence of toxin-encoding genes in Clostridium perfringens isolates.

\begin{tabular}{|c|c|c|c|c|c|c|c|c|c|}
\hline \multirow[t]{3}{*}{ Samples } & \multirow{3}{*}{$\begin{array}{c}\text { Number of } \\
\text { isolates }\end{array}$} & \multicolumn{8}{|c|}{ Toxin genes of Clostridium perfringens } \\
\hline & & \multicolumn{2}{|l|}{ Cpa } & \multicolumn{2}{|l|}{ Cpe } & \multicolumn{2}{|l|}{ Cpb2 } & \multicolumn{2}{|l|}{ NetB } \\
\hline & & No. isolates & $\%$ & No. isolates & $\%$ & No. isolates & $\%$ & No. isolates & $\%$ \\
\hline $\begin{array}{l}\text { Fecal samples from healthy } \\
\text { ostriches }\end{array}$ & 33 & 33 & 100 & 0 & 0 & 0 & 0 & 1 & 3.03 \\
\hline $\begin{array}{l}\text { Fecal samples from } \\
\text { diseased ostriches }\end{array}$ & 47 & 47 & 100 & 1 & 2.12 & 3 & 6.38 & 8 & 17.05 \\
\hline $\begin{array}{l}\text { Intestinal organs from } \\
\text { diseased ostriches }\end{array}$ & 36 & 36 & 100 & 0 & 0 & 2 & 5.55 & 7 & 19.44 \\
\hline Total & 116 & 116 & 100 & 1 & 0.77 & 5 & 4.31 & 16 & 13.79 \\
\hline
\end{tabular}


from them. It is revealed that there is one A nucleotide at $-58 \mathrm{bp}$ position deleted in $\operatorname{net} B$ sequences of Vietnam isolates compared to other net $B$ genes of $C$. perfringens isolates from other geographical regions in the world. The effect of this variation could be related to NetB expression regulation and need further studies.

\section{Conclusion}

This study is the first report of the prevalence and toxinotype characterization of $C$. perfringens isolates from ostriches in Vietnam. The data presented in this study confirm that Type A is the most prevalent among $C$. perfringens isolates from poultry. In addition, the study provides data emphasizing the role of NetB toxin in causing necrotic enteritis in ostriches.

\section{Authors' Contributions}

TTN carried out the experiments and drafted the manuscript. HV and TDN conceived the original idea, supervised the project, and revised the manuscript. All authors have read and approved the final manuscript.

\section{Acknowledgments}

The authors wish to thank Bacteriology Department, Institute of Veterinary Research and Development of Central Vietnam for providing C. perfringens isolates for positive controls of different toxinotypes. This study was supported by the Biotechnology Program grant, Ministry of Agriculture and Rural Development, Vietnam.

\section{Competing Interests} interests.

The authors declare that they have no competing

\section{Publisher's Note}

Veterinary World remains neutral with regard to jurisdictional claims in published institutional affiliation.

\section{References}

1. Zakeri, A. and Kashefi, P. (2012) Necrotic enteritis by Clostridium perfringens in Ostrich (Struthio camelus). World Appl. Sci. J., 16(6): 842-845.

2. Razmyar, J., Peighambari, S.M. and Zamani, A.H. (2017) Detection of a newly described bacteriocin, perfin, among Clostridium perfringens isolates from healthy and diseased ostriches and broiler chickens in Iran. Avian Dis., 61(3): 387-390.

3. Petit, L., Gibert, M. and Popoff, M.R. (1999) Clostridium perfringens: Toxinotype and genotype. Trends Microbiol., 7(3): 104-110

4. Prescott, J.F., Parreira, V.R. and Gohari, I.M., Lepp, D. and Gong, J. (2016) The pathogenesis of necrotic enteritis in chickens: What we know and what we need to know: A review. Avian Pathol., 45(3): 288-294.

5. Kiu, R. and Hall, L.J. (2018) An update on the human and animal enteric pathogen Clostridium perfringens. Emerg. Microbes Infect., 7(1): 1-15.

6. Rood, J.I., Adams, V. and Lacey, J., Lyras, D., McClane, B.A and Melville, S.B. (2018) Expansion of the Clostridium perfringens toxin-based typing scheme. Anaerobe, 53: 5-10.

7. Ronco, T., Stegger, M., Ng, K.L., Lilje, B., Lyhs, U.,
Andersen, P.S., Pedersen, K. (2017) Genome analysis of Clostridium perfringens isolates from healthy and necrotic enteritis infected chickens and Turkeys. BMC Res. Notes, 10(1): 270.

8. Smyth, J.A. and Martin, T.G. (2010) Disease producing capability of netB positive isolates of C. perfringens recovered from normal chickens and a cow, and netB positive and negative isolates from chickens with necrotic enteritis. Vet. Microbiol., 146(1-2): 76-84.

9. Keyburn, A.L., Portela, R.W., Sproat, K., Ford, M.E., Bannam, T.L., Yan, X., Rood, J.I. and Moore, R.J. (2013) Vaccination with recombinant NetB toxin partially protects broiler chickens from necrotic enteritis. Vet. Res., 44(1): 54.

10. Keyburn,A.L., Boyce, J.D., Vaz, P., Bannam,T.L., Ford, M.E., Parker, D., Di Rubbo, A., Rood, J.I. and Moore, R.J. (2008) NetB, a new toxin that is associated with avian necrotic enteritis caused by Clostridium perfringens. PLoS. Pathog., 4(2): e26

11. Yang, W.Y., Chou, C.H. and Wang, C. (2018) Characterization of toxin genes and quantitative analysis of netB in recrotic enteritis (NE)-producing and non-NE-producing Clostridium perfringens isolated from chickens. Anaerobe, 54: 115-120.

12. Quinn, P.J., Carter, M.E., Markey, B. and Carter, G.R. (1994) Clostridium species. In: Clinical Veterinary Microbiology. Wolfe Publishing, London, UK. p191-208.

13. Songer, J. and Bueschel, D. (1999) Multiplex PCR Procedure for Genotyping Clostridium perfringens. University of Arizona, USA.

14. Abildgaard, L., Sondergaard, T.E., Engberg, R.M., Schramm, A. and Højberg, O. (2010) In vitro production of necrotic enteritis toxin $\mathrm{B}, \mathrm{NetB}$, by netB-positive and netB-negative Clostridium perfringens originating from healthy and diseased broiler chickens. Vet. Microbiol., 144(1-2): 231-235.

15. Alimolaei, M., Ezatkhah, M. and Bafti, M.S. (2014) Genetic and antigenic typing of Clostridium perfringens isolates from ostriches. Infect. Genet. Evol., 28: 210-213.

16. Keokilwe, L., Olivier, A., Burger, W.P., Joubert, H., Venter, E.H. and Morar-Leather, D. (2015) Bacterial enteritis in ostrich (Struthio camelus) chicks in the Western Cape Province, South Africa. Poult Sci., 94(6): 1177-1183.

17. Zandi, E., Mohammadabadi, M.R., Ezzatkhah, M. and Esmailizadeh, A.K. (2014) Typing of toxingenic isolates of Colostridium perfringens by multiplex PCR in ostrich. Iran. J. Appl. Anim. Sci., 4(4): 795-801.

18. Heikinheimo, A. and Korkeala, H. (2005) Multiplex PCR assay for toxinotyping Clostridium perfringens isolates obtained from Finnish broiler chickens. Lett. Appl. Microbiol., 40(6): 407-411.

19. Ghoneim, N.H. and Hamza, D.A. (2017) Epidemiological studies on Clostridium perfringens food poisoning in retail foods. Rev. Sci. Tech., 36(3): 1025-1032.

20. Zhang, T., Zhang, W., Ai, D., Zhang, R., Lu, Q., Luo, Q. and Shao, H. (2018) Prevalence and characterization of Clostridium perfringens in broiler chickens and retail chicken meat in central China. Anaerobe, 54: 100-103.

21. Chalmers, G., Bruce, H.L., Hunter, D.B., Parreira, V.R., Kulkarni, R.R., Jiang, Y.F., Prescott, J.F. and Boerlin, P. (2008) Multilocus sequence typing analysis of Clostridium perfringens isolates from necrotic enteritis outbreaks in broiler chicken populations. J. Clin. Microbiol., 46(12): 3957-3964.

22. Mirzazadehghassab, A., Kalidari, G.A., Razmyar, J. and Tolooe, A. (2014) Prevalence of netb and Tpel Genes among Clostridium perfringens Isolates Obtained from Healthy and Diseased Ostriches (Struthio camelus). In: The $12^{\text {th }}$ Biennial Congress of the Anaerobe Society of the Americas, Chicago, Illinois, USA.

23. Razmyar, J., Rezaee, M., Movassaghi, A.R. and Shojadust, B. (2017) NetB negative Clostridium perfringens 
infection associated with acute necrotic enteritis in mynah (Acridotheres tristis), grey partridge (Perdix perdix) and Turkey (Meleagris gallopavo). Iran. J. Vet. Res., 9(2): 64-69.
24. Ezatkhah, M., Alimolaei, M. and Shahdadnejad, N. (2016)

The prevalence of netB gene in isolated Clostridium perfringens from organic broiler farms suspected to necrotic enteritis. Int. J. Enteric Pathog., 4(3): e35667.

\section{$* * * * * * * *$}

